\title{
Cortisol Responses to Stress in Allergic Children: Interaction with the Immune Response
}

\author{
A. Buske-Kirschbaum \\ Department of Biopsychology, Technical University of Dresden, Dresden, Germany
}

\section{Key Words}

Cortisol - Stress - Allergy · Atopic dermatitis - Allergic

asthma $\cdot$ Hypothalamus-pituitary-adrenal axis

\begin{abstract}
Allergic manifestations are increasingly common in infants and children. Accumulating evidence suggests that the 'epidemic' increase of childhood allergy may be associated with environmental factors such as stress. Although the impact of stress on the manifestation and exacerbation of allergy has been demonstrated, the underlying mechanisms of stressinduced exacerbation are still obscure. A growing number of studies have suggested an altered hypothalamus-pituitaryadrenal (HPA) axis function to stress in allergic children. It is speculated that a dysfunctional HPA axis in response to stress may facilitate and/or consolidate immunological aberrations and thus, may increase the risk for allergic sensitization and exacerbation especially under stressful conditions. In the present review the potential impact of a hyporesponsive as well as a hyperresponsive HPA axis on the onset and chronification of childhood allergy is summarized. Moreover, potential factors that may contribute to the development of an aberrant HPA axis responsiveness in allergy are discussed.

Copyright $\odot 2009$ S. Karger AG, Basel
\end{abstract}

(C) 2009 S. Karger AG, Basel

1021-7401/09/0165-0325\$26.00/0

Fax +4161306 1234

E-Mail karger@karger.ch

www.karger.com
Accessible online at:

www.karger.com/nim

\section{Allergy in Children - A Growing Problem}

The term 'allergy' refers to a familial or hereditary tendency to become sensitized to certain environmental or food substances such as dust mites, pollen, mold, or dander and to develop hypersensitivity reactions with an excessive production of immunoglobulin E (IgE). Allergic disorders mainly include atopic dermatitis (AD), allergic asthma (AA), allergic rhinitis (AR) and gastrointestinal allergies [1].

Allergy represents a global health issue affecting more than $20 \%$ of the population in Europe and the USA with increasing prevalence over the last decade. AD and AA are the most frequent chronic diseases in infancy and are estimated to affect $5-21 \%$ of the children in the industrialized Western countries $[2,3]$. Although often trivialized, allergy is one of the major causes of hospitalization in children younger than 15 years of age and impacts on and impairs family and social life quality and school performance [4]. The socioeconomic costs accrued by the management of the atopic patient are estimated at 10 billion EUR for direct costs related to hospitalization and treatment, and 19 billion EUR for indirect costs related to reduced productivity or absenteeism from work or school [2]. Regarding these data it seems imperative to understand the pathology of atopy and, moreover, to recognize and control factors triggering exacerbation of al-

Angelika Buske-Kirschbaum, $\mathrm{PhD}$

Department of Biopsychology, Technical University of Dresden DE-01062 Dresden (Germany)

Tel. +49 3514633 9798, Fax +49 35146339798

E-Mail buske@biopsych.tu-dresden.de 
lergic symptomatology. In general, atopy is described as a hereditary condition characterized by distinct immunoregulatory abnormalities. In sensitized individuals, exposure to environmental allergens leads to hypersecretion of allergen-specific IgE. Cross-binding of IgE molecules located on basophils and mast cells by the allergen results in the release of vasoactive and proinflammatory mediators being responsible for the acute symptoms of atopy such as redness of the skin, edema or pruritus in the $\mathrm{AD}$ patient or smooth muscle constriction, chest tightness or mucus in the AA subject (immediate allergic response) [5]. Allergen-presentation by dendritic cells initiates the late-phase response by activating T-helper (Th) cells secreting high amounts of interleukin (IL)-4, IL-5 and IL-13, reflecting a predominantly Th2 cytokinesecreting profile. The dominance of Th2 cytokines plays a key role in the chronification of allergic inflammation. IL-4 and IL-13 stimulate IgE synthesis and induce B cells to switch from other Ig isotypes to IgE. They further stimulate vascular cell adhesion molecule 1 (VCAM-1) expression allowing recruitment and invasion of eosinophils into sites of allergic tissue inflammation. IL-5 augments eosinophil production and stimulates eosinophils to secrete toxic proteins (i.e. eosinophil cationic protein) which are found to contribute to cell damage of the airway system and the skin [6,7]. Although the pivotal roles of immune dysfunctions in the development of allergic disease are undisputed, they cannot explain the rapid increase in the prevalence of allergic conditions.

One potential hypothesis to explain the increased prevalence of allergy is that other factors promoting allergic sensitization and subsequent immunopathology may have erased and/or increased. Beside other lifestyle factors, e.g. nutrition or environment exposure such as pollution, psychosocial stress has been discussed to significantly affect the development and maintenance of allergy [8]. A growing number of studies suggest that stressful experiences such as death of a family member, divorce, unemployment, or an increase in everyday problems may promote the onset and/or the exacerbation of allergic disease [911]. The importance of stress in triggering exacerbation of childhood allergy has been emphasized by others showing that high levels of emotional stress induced by divorce, moving or parenting difficulties increase the risk to develop AD or AA symptoms [12, 13]. Based on a survey commissioned by the American Psychological Association, stress is a growing problem among the general public in the USA with $48 \%$ of the Americans reporting that stress has increased over the past 5 years [14]. Regarding the relevance of stress in triggering atopic disease and fur- ther, the increase of the everyday stress load in the industrialized countries, it is tempting to speculate that increased life stress is one factor relevant to the 'epidemic of atopy'. Following this idea it may be crucial to better understand how stress affects allergic inflammatory processes and, moreover, which the communicating molecules of the psychoneuroimmunological interplay under stressful conditions might be. Since allergic sensitization and disease onset usually occur in early childhood, and the increase in allergy prevalence is particularly pronounced in infants and children $[2,15]$, research interest should be focused on this age group.

\section{Stress and Hypothalamus-Pituitary-Adrenal Axis Function in Allergic Children}

The hypothalamus-pituitary-adrenal (HPA) axis is considered to be a central integrative system being crucial in the successful physiological adaptation of the organism to stress. During stress corticotrophin-releasing hormone $(\mathrm{CRH})$ and arginine vasopressin, the principal hypothalamic regulators of the HPA axis are released. $\mathrm{CRH}$ stimulates the secretion of the adrenocorticotropin hormone (ACTH) from the anterior pituitary into the hypophyseal portal system via collateral fibers in the systemic circulation. ACTH leads to the secretion of glucocorticoids (GCs; cortisol in humans and corticosterone in rodents) from the adrenal cortex, the main target of ACTH. GCs are the final effectors of the HPA axis. GCs regulate multiple bodily functions and prepare the individual to cope with the demand of metabolic, physical and psychological stressors [16]. One important target organ controlled by the HPA axis is the immune system. GCs have profound immunosuppressive effects including immune functions known to be critically involved in allergic inflammation. For example, GCs inhibit dendritic cell maturation, leading to reduced allergen presentation to T cells $[17,18]$. GCs further induce apoptosis of eosinophils and basophils and have been shown to inhibit transmigration of these effector cells to the inflammatory site by downregulating leukocyte adhesion molecules, such as endothelial leukocyte adhesion molecule-1 (ELAM-1) or intercellular adhesion molecule-1 (ICAM-1) $[19,20]$. The potential role of GCs for the allergic inflammation has been further emphasized by data showing a close relationship between the circadian rhythm of cortisol and changes of basophil and eosinophil levels [21]. Others reported that after treatment with the cortisol synthesis inhibitor methyrapone, allergic 
subjects showed significant exacerbation of the allergic skin response [22]. Regarding the pivotal role of the HPA axis both in being highly responsive to stressful (psychosocial) stimuli, and in orchestrating the adaptive (immunological) response to this stressor, it may be important to study HPA axis functioning under stress in allergic children.

Using a laboratory stressor we found that children suffering from allergy show an aberrant HPA axis function. In particular, we could demonstrate that $\mathrm{AD}$ children show significantly attenuated cortisol levels in response to a standardized stressor (Trier Social Stress Test (TSSTC)), when compared to a non-atopic control group [23]. The TSST-C is a standardized psychosocial stress test consisting of public speaking (finishing a story in as exciting a manner as possible) and arithmetic tasks (serial subtraction) in front of an audience. The TSST-C has been repeatedly demonstrated to induce activation of the HPA axis and the sympathetic adrenomedullary system [23-25]. Reduced cortisol responses to the stressor in our patients could not be explained by previous or concurrent treatment with corticosteroids, or differences in personality variables. Trying to further elucidate HPA axis dysfunction in the allergic child, we studied cortisol responses to the TSST-C in AA children. We reported reduced cortisol levels after the TSST-C in AA children suggesting that a hyporesponsive HPA axis may not be a characteristic feature limited to skin atopy, but may rather be a phenomenon generally linked to allergic inflammation regardless of the organ affected [26]. This idea has been confirmed by others showing lower cortisol responses to a stressful laboratory procedure, i.e. blood sampling in adolescents with different forms of allergy, i.e. AD, AA and primarily AR [27]. It is of note, however, that the data suggesting a hyporesponsive HPA axis to stress in allergic children have been obtained in studies using standardized acute laboratory stressors. To further emphasize a role of a dysfunctional HPA axis in stress-induced disease progression, it may be important to study HPA axis responsiveness in a more 'naturalistic' setting including everyday life stressors as well as chronic stress conditions. Wolf et al. [28] reported that chronic stress and low socioeconomic status are linked to elevated cortisol levels in healthy but not in AA children. This observation may point to a lower HPA axis responsiveness to chronic home stress in allergic children and thus may support the laboratory findings previously discussed.

These data in aggregate strongly support the idea that HPA axis responsiveness to stress may be reduced in the chronic allergic child. However, the observation that childhood AA and AD are linked to a reduced HPA reactivity does not necessarily implicate that HPA axis dysfunction is of pathological relevance. Little is known about whether a reduced HPA axis response to stressful (or other) stimuli increases the risk of allergic sensitization or chronification of the disease. Further, it remains to be determined whether a hyporesponsive HPA axis is key in the stress-allergy relationship in that an inappropriate response of the system under stressful conditions facilitates or even triggers the (immuno)pathology of allergy. Finally, if a hyporesponsive HPA axis is of pathological relevance, which are the factors that cause aberration of HPA axis functioning.

\section{Altered HPA Axis Responsiveness in Allergic Children - A Risk Factor in Childhood Allergy?}

It is well documented that the HPA axis represents a major immunoregulatory system that plays a pivotal role in balancing the immune response especially under stressful conditions. Due to the immunosuppressive and anti-inflammatory properties of GCs it has been emphasized that an appropriate (re)activity of the HPA axis may be essential to control inflammation and to prevent an overshooting of the immune response which may be damaging for the host. In turn, a chronic failure to raise an adequate HPA axis response may contribute to pathology [29]. This idea has been strongly supported by animal and human data showing that hyporesponsiveness of the HPA axis to stressful or pharmacological stimuli is closely linked to an increased susceptibility to and severity of inflammatory disease including allergic inflammation such as adult AD [30-34]. However, data showing a pathological significance of HPA axis dysfunction in the process of sensitization and/or the manifestation of (childhood) allergy are still elusive. Sensitization to environmental allergens is generally observed during the first month of life and may or may not be linked to allergic symptoms [35]. Thus, the potential role of an altered HPA axis function in the allergic sensitization process, i.e. the initiation of a strong infantile specific IgE antibody production, is difficult to study. We found that cortisol responses to stress in newborns at high risk for later development of atopic disease by virtue of elevated IgE cord blood levels and parental allergies were increased [36]. This observation has been recently supported by Ball et al. [37] demonstrating a hyperreactive HPA axis to stress in 6-month-old infants with an allergic mother. These findings may be of relevance suggesting that during the 
early period of allergy development the HPA axis may be rather hyper- than hyporeactive to stress. Regarding the anti-inflammatory properties of GCs, however, the idea that increased levels of endogenous cortisol after stress may increase the risk for the inception of the allergic inflammatory process appears paradox. It is important to recognize that in the last decade, the effect of the HPA axis on immunity has been specified in that GCs are not totally immunosuppressive but rather shape the immune system in a dynamic way by their different, sometimes diametrically opposite effects on the different components of the immune response. GCs drive a Th2 shift by suppressing IL-12, the main Th1 inducer while the secretion of IL- 4 and IL-10, which both promote the Th2 response, are stimulated. GCs further have a direct stimulatory effect on Th2 cells [38, 39]. As previously discussed, the dominance of the Th2-immune response is a key factor in allergy-inducing IgE hypersecretion and eosinophil recruitment and activation [6]. There are several reports showing that a polarization towards a Th2-dominant immune profile as indicated by high IgE levels or a reduced capacity to secrete IFN- $\gamma$ can be already identified in infants at high risk for later atopic disease [40, 41]. Increased cortisol levels during stress episodes in the predisposed child may lead to an additional shift towards a Th2-dominant immune profile that may facilitate the onset and/or manifestation of allergic inflammation. Another potential detrimental effect of higher stress-induced cortisol levels that may promote manifestation of allergic disease involves the induction of IgE secretion by GCs. Ray et al. [42] reported an enhancement of IgE production after GC treatment by mononuclear cells in vitro. Interestingly, augmentation of $\mathrm{IgE}$ secretion was noted only in mononuclear cells from atopic, but not in cells from non-atopic subjects suggesting an altered sensitivity of IgE-producing B cells for GCs in atopics. More recently, it has been reported that GCs increase IL-4-stimulated IgE formation probably via upregulation of the costimulatory molecule CD40 ligand (CD40L) on Th cells. Binding of the CD40L to the B-cell CD40 receptor causes resting B-cell activation and IgE isotype switching [43, 44]. Regarding these findings, the idea that hyperresponsiveness of the HPA axis in infants at high allergic risk may promote sensitization and subsequent IgE hyperproduction does not appear too speculative. Thus, we propose that increased cortisol levels to early stress experiences may further skew the already Th2-biased immune response of the predisposed child towards an even more distinct Th2 predominance. Augmentation of Th2-related cytokines such as IL-4 and IL-5 may initiate and man- ifest allergic inflammation by mast cell stimulation, $\operatorname{IgE}$ isotype switching and eosinophil activation. It has been found that GCs and IL-4 act synergistically to induce IgE production by B cells. In this study, GCs had an even more profound effect on specific IgE formation in sensitized subjects than IL-4 [45]. Thus, elevated levels of endogenous cortisol in stressful situations may be directly related to specific IgE hypersecretion.

It has become clear that hyperresponsiveness of the HPA axis in infants predisposed to allergy could contribute to sensitization and later manifestation of the disease. However, it is also evident that this finding contrasts sharply with the data reported previously suggesting a hyporesponsive HPA axis in children already suffering from allergic disease. To explain these diametrical findings, it could be speculated that with the onset or the chronification of the disease, the HPA axis may switch from a hyper- to a hypoactive state. To date, no convincing data are available lending support to this assumption; however, there are certain findings that would strengthen such a hypothetical change in HPA axis functioning. A growing body of data suggests that proinflammatory cytokines such as IL-1, IL- 6 or TNF- $\alpha$ stimulate HPA axis activity. It has been proposed that in chronic inflammatory conditions, persistently increased levels of endogenous cortisol in response to proinflammatory cytokine release may lead to hyporesponsiveness of the HPA axis probably due to increased negative feedback mechanisms [46]. Accordingly, it may be tempting to speculate that in allergic children, manifestation and subsequent longterm release of pro-inflammatory cytokines drive the HPA axis from a hyperactive to a hypoactive response profile due to analogous mechanisms. Alternatively, animal data suggest that chronic stress may result in a change of HPA axis responsiveness. Mice subjected to mild stress initially showed elevated GC responses; however, after 29 days of stress exposure significantly blunted GC responses were found [47]. Most recently, these findings were supported by Reber et al. [48]. Studying the effect of chronic stress on experimental colitis in mice he could demonstrate an initial rise of GC levels in response to subordinate colony housing stress; however, after prolonged exposure to the stressful setting (19 days) a significant decrease of GC levels was noted. Interestingly, attenuated HPA axis responsiveness in response to the chronic stressor was linked to higher levels of pro-inflammatory and anti-inflammatory cytokines and, further, to increased colonic inflammation. Others have emphasized that chronic stress during early life potentially has a significant effect on the HPA axis and predisposes 
to HPA axis dysfunction in later life. In this model, early life stress is discussed to be linked to hypersecretion of CRF resulting in long-term downregulation of adenohypophyseal CRF receptors and depressed ACTH and cortisol responses $[49,50]$. These findings are of specific interest since the allergic child suffers from significant (chronic) everyday stress and social problems due to the allergic condition and the experience of chronic stress exposure in these children generally starts very early in life [51]. It is important to note that the mechanisms discussed above are mainly built on animal data. To date it is still speculative whether these factors are also involved in the potential change of an initially hyperresponsive into a hyporesponsive HPA axis response in the allergic child.

In a previous section of this overview the potential role of a hyperresponsive HPA axis in the sensitization and manifestation of childhood allergy has been emphasized. The observation that an already established, ongoing allergic inflammation is linked to a suppressed function of the HPA axis may likewise be of particular clinical significance. As mentioned earlier, GCs are highly effective in the clinical management of allergic disease [29]. The failure to rise an appropriate level of endogenous GCs has been found to be linked to an increased risk to develop chronic inflammatory disease with more severe clinical symptoms when stimulated with proinflammatory agents [30-34]. GCs inhibit the transcription of allergy-relevant cytokines such as IL-4 and IL-5 which are key cytokines in triggering allergic inflammation. GCs further are found to inhibit eosinophil transmigration by downregulation of adhesion molecules such as intercellular adhesion molecule-3 and to induce apoptosis of eosinophils [31]. Consequently, a blunted HPA axis reactivity with reduced levels of endogenous cortisol in the allergic child may facilitate a dysregulation of these parameters, i.e. an overshooting of the allergic (inflammatory) response leading to exacerbation of allergic symptoms. This effect may be expected to be even more pronounced under stressful conditions when the HPA axis should be activated. In fact, the circadian rhythm of cortisol closely corresponds with eosinophil levels with highest eosinophil levels at the nocturnal nadir of serum cortisol [52]. Others found a close link between low cortisol levels at night and high circulating histamine levels and nocturnal wheezing in asthmatic subjects [53]. Landstra et al. [54] reported significantly lower cortisol levels in AA children during the night which were associated with lower forced expiratory volume in $1 \mathrm{~s}$, nocturnal airway obstruction, wheeze and chest tightness supporting a close link between endogenous low cortisol levels and allergic symptomatology. Recently, our group found that reduced cortisol responses to stress in adult $\mathrm{AD}$ patients were accompanied by elevated eosinophil and IgE levels, increased proinflammatory cytokines as well as exacerbation of skin symptomatology $24 \mathrm{~h}$ later [55]. A direct causal relationship between a reduced HPA axis function and atopic symptoms has been suggested by Laue et al. [55]. Healthy volunteers treated with the GC receptor antagonist RU-486 for 7-14 days developed AD symptomatology such as erythema and skin eruptions. None of the subjects had a prior history of atopy.

The data discussed so far strongly support the idea that childhood allergy may be initiated or progress in settings of hyper- or hypoactivity of the HPA axis (fig. 1). Some potential pathways of how abnormal high or low endogenous GC levels under stress may contribute to the immunopathology have been discussed. However, these concepts are still speculative and have to be confirmed. Future studies are needed investigating the HPA axis and, importantly, its stress-induced cross-talk through allergy-relevant effector cells and cytokines in allergic patients at different stages of the disease. Evaluating HPA axis responsiveness to stressful stimuli in 'at-risk babies/ infants', in infants during the first months of the disease, and in children at chronic symptomatic stage may help to better understand the role of the HPA axis in the development and, further, the stress-induced outburst of allergic symptoms. Importantly, besides studying the pathological consequences of altered HPA axis function, future research efforts should be focused on identifying factors crucial for the development of HPA axis dysfunction. As reviewed recently [56], genetic factors, i.e. variants of the GC receptor gene, may contribute to the interindividual differences in HPA axis function including baseline levels of cortisol or the cortisol awakening response. Others characterized polymorphisms of the $\mathrm{CRH}$ receptor (CRHR1) or the ACTH receptor (MC2R) leading to a decreased release of ACTH by the pituitary and/or a decreased adrenal responsiveness to ACTH resulting in lower GC secretion $[57,58]$. Thus, genetic factors are good candidates to explain changes in HPA axis function that may lead to maladaptive immune development and regulation. The observation that maternal allergy predicts higher neonatal cortisol responses to stress and moreover a higher risk to develop allergic disease in later life than paternal allergy $[34,59]$ further points to the relevance of the intrauterine environment in the development of HPA axis dysfunction in childhood allergy. In recent years a concept known as 'fetal programming' has gained con- 


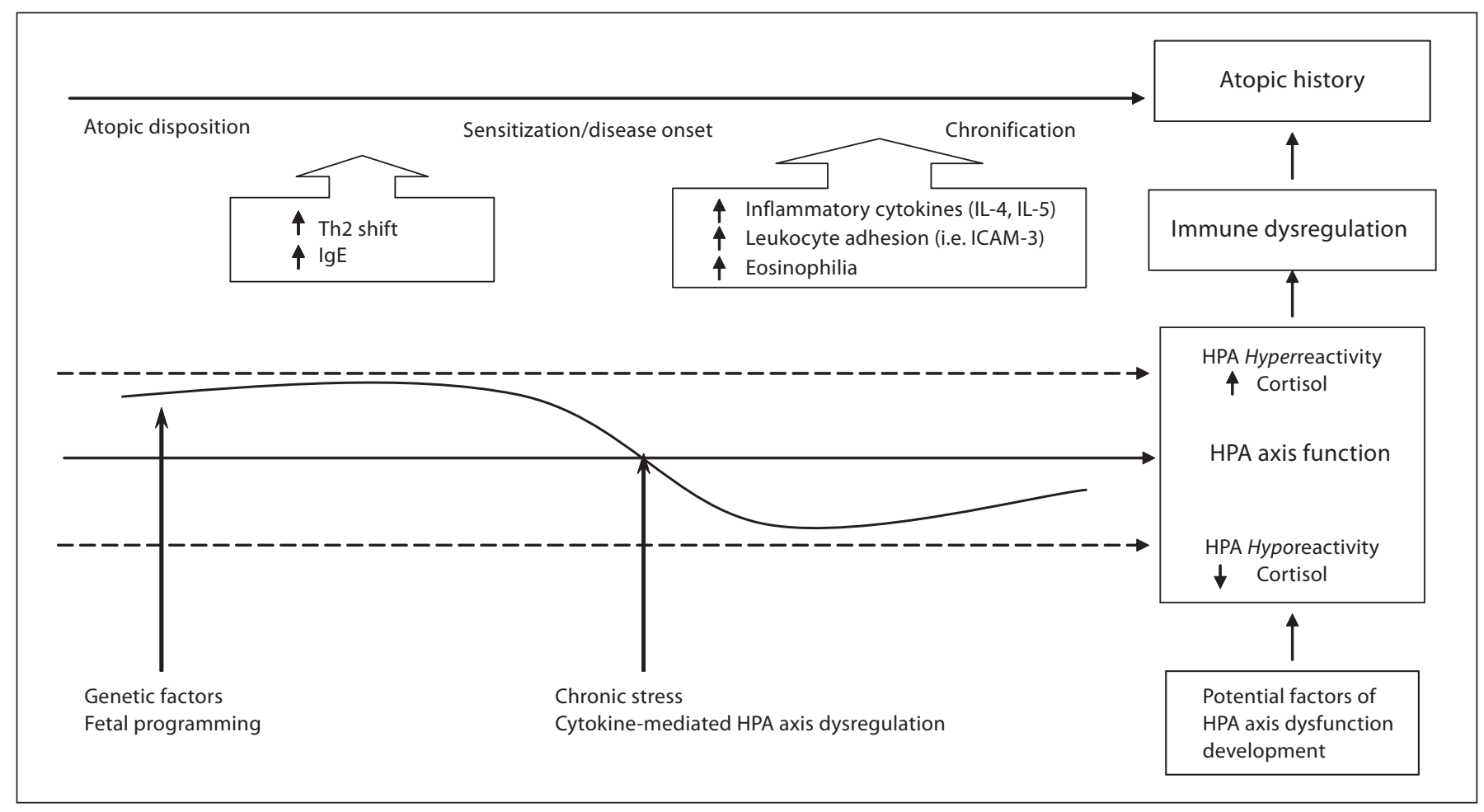

Fig. 1. HPA axis dysfunction - a key factor in atopic disease. Atopic disposition in early infancy is associated with a hyperresponsiveness of the HPA axis to stress $[36,37]$. The mechanisms leading to HPA axis dysfunction in infants predisposed to later allergy are still elusive; however, genetic factors [56] or fetal programming [60] have been discussed. We propose that elevated levels of endogenous cortisol under stressful conditions in the predisposed child skew an already Th2-biased immune response towards an even more distinct Th2 dominance increasing the risk for allergic sensitization and onset of allergic disease. Cortisol-induced stimulation of IL-4-induced IgE production by B cells may potentiate this effect [43]. During disease progression, HPA axis hyperresponsiveness switches into HPA axis hyporesponsiveness. Factors responsible for the switch in HPA axis functioning are unknown;

siderable interest. It has been proposed that exposure to adverse intrauterine (and early extrauterine) influences imprints on the fetus a pattern of physiological activity resulting in 'programs' in the developing brain leading to significantly altered physiological functioning and vulnerability to various diseases [60]. Extensive research both in animals and humans over the last years has shown that the HPA axis is highly susceptible to pre- and postnatal programming. In animals, stress in utero has been linked to altered HPA axis function such as a shift in the circadian rhythm of GC secretion or a hyperresponsiveness of the HPA axis to stress [61]. Accordingly, neonatal however, dysregulation by chronic inflammatory processes with prolonged secretion of proinflammatory cytokines [46] or chronic stress [49] due to the allergic condition and related social problems could be involved. The failure of the chronic allergic child to raise an appropriate cortisol response in stressful situations which may essential to control the inflammatory response, i.e. the secretion of inflammatory cytokines, leukocyte adhesion and eosinophil activation, increases the risk of (stress-induced) exacerbation and chronification of the disease. In the aggregate, we propose that childhood allergy can be initiated or progress in settings of a dysfunctional HPA axis. Due to its important immunoregulatory properties, a hyperreactive as well as a hyporeactive HPA axis facilitate immune dysregulation and may initiate and promote an atopic disease history.

stress, i.e. social isolation or maternal deprivation, were found to be associated with long-lasting changes of HPA axis function including elevated basal cortisol levels or an increased and prolonged HPA axis response to stress [62, 63]. Comparable data have been reported also in humans suggesting a link between high levels of prenatal or early life stress and altered HPA axis functioning in later childhood $[64,65]$. These data emphasize that aversive factors in utero or in the neonatal environment, independent of a genetic influence, affect the developing HPA axis and may imprint an altered 'program' of HPA axis (re)activity leading to a long-term maladaptive behavioral and/or 
immune response. The imprinting of an altered 'program' of HPA axis functioning by the intrauterine or the early extrauterine environment could be of specific significance in the child at high risk for atopy. Pregnancy is associated with a strong skewing towards a Th2 cytokine pattern which downregulates harmful cytokines and enables the survival of the fetus [66]. In general, the immune deviation towards Th2-type immunity is converted to a balanced Th1/Th2-immune response pattern dur- ing the first years of life [67]. It is speculated that in atopic children the postnatal process of this conversion is defective leading to a consolidation of Th2 immunity. Following this model we propose that an altered HPA axis functioning due to fetal programming additionally consolidates and potentiates the Th2 dominance in these children and thus increases the risk of immune deviation and early allergic sensitization (fig. 1).

\section{References}

1 Gold MS, Kemp A: Atopic disorders in childhood. Med J Aust 2005;182:298-304.

2 European White Paper on Allergy, 1997, Brussels.

3 World Health Organization: Prevention of Allergy and Allergic Asthma. Geneva, WHO, 2003.

4 Caroll CL, Balkrishnan R, Feldman SR, Fleischer AB Jr, Manuel JC: The burden of atopic dermatitis: impact on the patient, family and society. Pediatr Dermatol 2005; 22:192-199.

5 Umetsu DT, DeKruyff RH: The regulation of allergy and asthma. Immunol Rev 2006;212: 238-255.

6 Allam JP, Bieber T, Novack N: Recent highlights in the pathology of atopic eczema. Int Arch Allergy Immunol 2005;136:191-197.

7 Larche M, Robinson DS, Kay AB: The role of $T$ lymphocytes in the pathogenesis of asthma. J Allergy Clin Immunol 2003;111:450463.

8 Leonardi S, Miraglia del Giudice M, La Rosa M, Bellanti JA: Atopic disease, immune system, and environment. Allergy Asthma Proc 2007;28:410-417.

9 Buske-KIrschbaum A, Geiben A, Hellhammer D: Psychobiological aspects of atopic dermatitis. Psychother Psychosom 2001;70: 6-16.

10 Viq RS, Forsythe P, Vliagoftis H: The role of stress in asthma: insight from studies on the effect of acute and chronic stressors in models of airway inflammation. Ann NY Acad Sci 2006;1088:65-77.

11 Kilpelainen M, Koskenvuo M, Helenius H, Terho EO: Stressful life events promote the manifestation of asthma and atopic disease. Clin Exp Allergy 2002;32:256-263.

12 Bockelbrink A, Heinrich J, Schäfer I, Zutavern $A$, Borte $M$, Herbarth $\mathrm{O}$, Schaaf B, von Berg, A, Schäfer T: Atopic eczema in children: another harmful sequel of divorce. Allergy 2006;61:1397-1402.

13 Sandberg S, Paton J, Ahola S, McCann D, McGuiness D, Hillary C, Oja H: The role of acute and chronic stress in asthma attacks in children. Lancet 2000;356:982-987.
14 American Psychological Association: Stress in America. Report 2007. Washington, APA, 2007.

15 Ahberg N, Hesselmar B, Aberg B, Eriksson B: Increase of asthma, allergic rhinitis and eczema in Swedish schoolchildren between 1979 and 1991. Clin Exp Allergy 1995;25: 815-819.

16 Chrousos GP: Organization and integration of the endocrine system; in Sperlin J (ed): Pediatric Endocrinology. Philadelphia, Saunders, 2002, pp 1-14.

17 Franchimont D, Kino T, Galon J, Meduri GU, Chroussos G: Glucocorticoids and inflammation revisited: the state of the art. Neuroimmunomodulation 2002;10:247-260.

18 Piemonti L, Monti P, Allavena P, Sironi M, Soldini L, Leone BE, Socci C, Di Carlo V: Glucocorticoids affect human dendritic cell differentiation and maturation. J Immunol 1999;162:6473-6481.

19 Maegher LC, Cousin JM, Seckl JR, Haslett C: Opposing effects of glucorticoids on the rate of apoptosis in neutrophilic and eosinophilic granulocytes. J Immunol 1996;156:44224428.

20 Cronstein BN, Kimmel SC, Levin RI, Nartiniuk F, Weissmann G: A mechanism for the anti-inflammatory effects of corticosteroids: the glucocorticoid receptor regulates leukocyte adhesion to endothelial cells and expression of endothelial-leukocyte adhesion molecule-1, and intercellular adhesion molecule. Proc Natl Acad Sci USA 1995;89:99919995.

21 Schleimer RP: Interactions between the hypothalamic-pituitary-adrenal axis and allergic inflammation. J Allergy Clin Immunol 2000;106:S270-S274.

22 Herrscher RF, Kasper C, Sullivan TJ: Endogenous cortisol regulates immunoglobulinE-dependent late phase reactions. J Clin Invest 1992;90:596-603.

23 Buske-Kirschbaum A, Jobst S, Wustmans A, Kirschbaum C, Rauh W, Hellhammer DH: Attenuated free cortisol response to psychosocial stress in children with atopic dermatitis. Psychosom Med 1997;59:419-426.
24 Gerra G, Zaimovic A, Zambelli U, Timpano M, Reali N, Bernasconi S, Brambilla F: Neuroendocrine responses to psychological stress in adolescents with anxiety disorders. Neuropsychobiology 2000;42:82-92.

25 Ellenbogen MA, Hodgins S, Walker CD, Couture S, Adam S: Daytime cortisol and stress reactivity in the offsprings of parents with bipolar disorder. Psychoneuroendocrinology 2006;31:1164-1180.

26 Kirschbaum A, von Auer K, Krieger S, Weis S, Rauh W, Hellhammer DH: Blunted cortisol responses to psychosocial stress in asthmatic children: a general feature of atopic disease? Psychosom Med 2003;65:806-810.

27 Wamboldt MZ, Laudenslager M, Wamboldt FS, Kelsay K, Hewitt J: Adolescents with atopic disorders have an attenuated cortisol response to laboratory stress. J Allergy Clin Immunol 2003;111:509-514.

28 Wolf J, Nicholls E, Chen E: Chronic stress, salivary cortisol, and $\alpha$-amylase in children with asthma and healthy children. Biol Psychol 2008;78:20-28.

29 Chrousos G: The hypothalamus-pituitaryadrenal axis and immune-mediated inflammation. N Engl J Med 1995;332:1351-1362.

30 Eskandari F, Sternberg E: Neural-immune interactions in health and disease. Ann NY Acad Sci 2002;966:20-27.

31 Franchimont D, Kino T, Galon J, Meduri GU, Chrousos G: Glucocorticoids and inflammation revisited: the state of the art. Neuroimmunomodulation $\quad 2002 ; 10: 247-$ 260.

32 Cash JM, Crofford LJ, Gallucci WT, Sternberg EM, Gold PW, Chrousos GP, Wilder RL: Pituitary-adrenal axis responsiveness to ovine corticotrophin releasing hormone in patients with rheumatoid arthritis treated with low-dose prednisone. J Rheumatol 1992;19:1692-1696.

33 Heesen C, Gold SM, Huitinga I, Reul JM: Stress and hypothalamic-pituitary-adrenal axis function in experimental autoimmune encephalomyelitis and multiple sclerosis - a review. Psychoneuroendocrinology 2007;32: 604-618. 
34 Buske-Kirschbaum A, Geiben A, Höllig H, Morschbäuser E, Hellhammer DH: Altered responsiveness of the hypothalamus-pituitary-adrenal axis and the sympathetic adrenomedullary system to stress in patients with atopic dermatitis. J Clin Endocrinol Metabol 2002;87:4245-4251.

35 Wahn U, von Mutius E: Childhood risk factors for atopy and the importance of early intervention. J Allergy Clin Immunol 2001; 107:567-574.

36 Buske-Kirschbaum A, Fischbach S, Rauh W, Hanker J, Hellhammer DH: Increased responsiveness of the hypothalamus-pituitary-adrenal axis to stress in newborns with atopic disposition. Psychoneuroendocrinology 2004;29:705-711.

37 Ball TM, Minto J, Anderson D, Halonen M: Circadian rhythms and stress responses in infants at risk for allergic disease. J Allergy Clin Immunol 2006;117:306-311.

38 Elenkov IJ: Glucocorticoids and the Th1/ Th2 balance. Ann NY Acad Sci 2004;1024: 138-146.

39 Calcagni E, Elekov I: Stress system activity, innate and T-helper cytokines, and susceptibility to immune-related disease. Ann NY Acad Sci 2006;1069:62-76.

40 Edenharter G, Bergmann RL, Bergmann KE, Wahn V, Forster J, Zepp F, Wahn U: Cord-blood-IgE as risk factor and predictor for atopic disease. Clin Exp Allergy 1998;28: 671-678.

41 Rinas U, Horneff G, Wahn V: Interferon- $\gamma$ production by cord blood mononuclear cells is reduced in newborns with a family history of atopic disease and independent from cord blood IgE levels. Pediatr Allergy Immunol 1993;4:60-64.

42 Ray A, Hemady Z, Rocklin RE: Glucocorticoid-induced enhancement of IgE synthesis. Allergy Proc 1987;8:81-84.

43 Barnes PJ: Corticosteroids, IgE, and atopy. J Clin Invest 2001;107:265-266.

44 Jabara HH, Brodeur SR, Geha RS: Glucocorticoids upregulate CD40 ligand expression and induce CD40L-dependent immunoglobulin isotype switching. J Clin Invest 2001;107:371-378.

45 Cho YJ, Hong SJ, Moon HB: Hydrocortisone enhances allergen-specific IgE production by peripheral blood mononuclear cells from atopic patients with high serum allergenspecific IgE levels. Clin Exp Allergy 2000;30: 1576-1581.

46 Rivier C: The hypothalamus-pituitary-adrenal axis response to immune signals; in Ader R, Felten DL, Cohen N (eds): Psychoneuroimmunology. San Diego, Academic Press, 2001, vol 1.
47 Murison R, Milde AM: Long-term effects of two animal stress procedures on corticosterone: models for PTSD (abstract). Berlin, International Society of Psychoneuroendocrinology, 1999.

48 Reber SO, Birkeneder L, Veenema AH, Obermeier F, Falk W, Straub RH, Neumann I: Adrenal insufficiency and colonic inflammation after a novel chronic psychosocial stress paradigm in mice: implications and mechanisms. Endocrinology 2007;148:670682.

49 Heim C, Nemeroff CB: Neurobiology of early life stress: clinical studies. Semin Clin Neuropsychiatry 2002;7:147-159.

50 Heim C, Newport DJ, Bonsall R, Miller AH, Nemeroff CB: Altered pituitary-adrenal axis responses to provocative challenge tests in adult survivors of childhood abuse. Am J Psychiatry 2001;158:575-581.

51 Varni JW, Wallander JL: Pediatric chronic disabilities; in Routh DK (ed): Handbook of Pediatric Psychology. New York, Guilford Press, 1988.

52 Schleimer RP: Interactions between the hypothalamic-pituitary axis and allergic inflammation. J Allergy Clin Immunol 2000; 106:S270-S274.

53 Barnes P, Fitzgerald G, Brown M, Dollery C: Nocturnal asthma and changes in circulating epinephrine, histamine, and cortisol. $\mathrm{N}$ Engl J Med 1980;303:263-267.

54 Landstra AM, Postma DS, Boezen M, van Aalderen MC: Role of serum cortisol levels in children with asthma. Am J Respir Critical Care Med 2002;165:708-712.

55 Laue L, Lotze MT, Chrousos GP, Barnes K, Loriaux DL, Fleisher TA: Effect of chronic treatment with the glucocorticoid antagonist RU-486 in man. Toxicity, immunological and hormonal aspects. J Clin Endocrinol Metab 1990;71:1474-1480.

56 Wüst S, Federenko IS, van Rossum EF, Koper JW, Kumsta R, Entringer S, Hellhammer DH: A psychobiological perspective on genetic determinants of hypothalamus-pituitary-adrenal axis activity. Ann NY Acad Sci 2004;1032:52-62.
57 Tantisira KG, Lake S, Silverman ES, Palmer LJ, Lazarus R, Silverman EK, Liggett SB, Gelfand EW, Rosenwasser LJ, Richter B, Israel E, Wechsler M, Gabriel S, Altshuler D, Lander E, Drazen J, Weiss ST: Corticosteroid pharmacogenetics association of sequence variants in CRHR1 with improved lung function in asthmatics treated with inhaled corticosteroids. Hum Mol Genet 2004;13:1353-1369.

58 Slawik M, Reisch N, Zwermann O, MaserGluth C, Stahl M, Klink A, Reinecke M, Beuschlein F: Characterization of an adrenocorticotropin (ACTH) receptor promoter polymorphism leading to decreased adrenal responsiveness to ACTH. J Clin Endocrinol Metabol 2004;89:3131-3137.

59 Ruiz RGG, Kemeny DM, Price JF: Higher risk of infantile atopic dermatitis from maternal atopy than from paternal atopy. Clin Exp Allergy 1992;22:762-766.

60 De Weerth C, Buitelaar JK, Mulder EJH: Prenatal programming of behaviour, physiology and cognition. Neurosci Biobehav Rev 2005; 29:207-208.

61 Matthews SG: Early programming of the hypothalamus-pituitary-adrenal axis. Trends Endocrinol Metabol 2002;13:373-380.

62 Sandstrom NJ, Hart SR: Isolation stress during the third postnatal week alters radial arm maze performance and corticosterone levels in adulthood. Behav Brain Res 2005;30:289296.

63 Levine S, Mody T: The long-term psychobiological consequences of intermittent postnatal separation in the squirrel monkey. Neurosci Biobehav Rev 2003;27:83-89.

64 Van den Berg BR, Van Calster B, Smits T, Van Huffel S, Lagae L: Antenatal maternal anxiety is related to HPA-axis dysregulation and self-reported depressive symptoms in adolescence: a prospective study on the fetal origins of depressed mood. Neuropsychopharmacology 2008;33:536-545.

65 Gutteling BM, de Weerth C, Buitelaar JK: Prenatal stress and children's cortisol reaction to the first day of school. Psychoneuroendocrinology 2005;30:541-549.

66 Yabuhara A, Macaubas C, Prescott SL, Venaille TJ, Holt BJ, Habre W, Sly PD, Holt PG: Th2-polarized immunological memory to inhalant allergens in atopics is established during infancy and early childhood. Clin Exp Allergy 1997;27:1261-1269.

67 Von Heertzen LC: Maternal stress and T-cell differentiation of the developing immune system: possible implications for the development of asthma and atopy. J Allergy Clin Immunol 2002;109:923-928. 